\title{
A Literature Review of the Concepts of Resilience and Sustainability in Group Decision-Making
}

\author{
Ali Aghazadeh Ardebili * (1) and Elio Padoano \\ Department of Engineering and Architecture, University of Trieste, Via Alfonso Valerio 6/1, 34127 Trieste, Italy; \\ padoano@units.it \\ * Correspondence: ali.aghazadehardebili@phd.units.it; Tel.: +39-327-1975278
}

Received: 29 January 2020; Accepted: 20 March 2020; Published: 25 March 2020

\begin{abstract}
The most critical decisions usually involve several decision makers with different roles and opportunities to commit key resources. Several group decision-making (GDM) approaches can support the identification of a joint or compromise decision in less conflicting settings, where there is a group of subjects (e.g', partners) who pursue a common overall objective. However, considering the uncertainty in future events and complexity of modern-day systems, decision processes do not always produce beneficial results or give the participants a positive perception of their role in the process. Group decision-making should then take into consideration some aspects that might insure future resilience and sustainability, particularly the achievement of the objectives in view of future risks and the transparency and participation that are needed to limit problems in the implementation phase of the decision. The literature survey presented in this study identified a research gap regarding GDM. Differently from traditional GDM, which was first discussed in the early 1980s and whose body of knowledge is pretty defined, resilient and sustainable GDM (R\&S GDM) is fairly new. The main objective of this study is then identifying the main attributes for supporting sustainable and resilient group decisions. To this aim, a preliminary focused systematic review was conducted to study the existing group decision-making methods in the literature and how the concepts of sustainability and resilience have been employed. After defining the search keywords and exclusion criteria for the individuation of the articles, the first screening process was carried out and the most relevant articles were selected. The last steps of the systematic review were the classification of the articles and the full paper examination to extract the main factors of R\&S GDM. Seven attributes were listed as the key factors of R\&S GDM. In light of those factors, a group decision process concerning an injection moulding line in Tajikistan was investigated. The case study highlighted that over self-confidence, information flow and transparency were the main reasons for faulty decisions, thus suggesting that information system and information fluidity play an important role in R\&S GDM. Finally, the most important managerial implications of R\&S GDM are reported.
\end{abstract}

Keywords: group decision-making; group decision performance; group decision important factors; group decision attribute; resilient decision-making; sustainable decision-making; information flow; decision failure; resilient and sustainable group decision-making (R\&S GDM)

\section{Introduction}

Different multi-criteria decision-making methods are available to support complex decisions, which usually employ the decision maker's (DM) preferences to weight the criteria and prioritize the alternative courses of action (solutions). These methods are mostly designed to rank solutions and select the best one for a single DM. However, in the case of several decision makers or stakeholders with decision power, the situation can be different. Making joint decisions is, for instance, an important part of any business run by a group of partners. In such cases, even in the presence of an overall common 
goal, finding the best choice that is compatible with all requirements and concurrently relevant to all DMs' preferences is a challenge. For instance, it can be required that some subjects represent other key partners' goals, even if they do not actually participate in the decision process. Further, the uncertainty of future events and the complexity of the system in which the decisions are made must be taken into consideration. It is therefore important to identify analysis and evaluation methods that can provide "resilient decisions", which are able to ensure dynamic equilibrium of the system by correcting, minimizing or avoiding the effects of unforeseen events. As highlighted in the following sections, "resilient" and "sustainable" are here interpreted as attributes of the decision-making process and results, while, in many other studies, they are used as criteria in the evaluation model. Then, after identifying the main factors, the second step was to appraise the outcome list to evaluate the role of each factor in a real case group decision.

The core of this study was a systematic review of the literature in order to individuate a set of the main factors that influence the resilience and sustainability of decision-making. The identified factors were then analyzed with specific reference to a real case of group decision. Consequently, the research objectives were refined across two stages. In the first stage we developed a systematic review to answer broad research questions (RQs) and the second stage is the case study concerning group decisions in a production line in Tajikistan, in which the actual influence of the identified factors on decisions is investigated.

To sum up, this article aims to achieve two types of objectives. The general objectives are finding research subjects, themes and gaps in the published research on group decision-making (GDM) where resilience and sustainability are considered. To this aim, 38 papers were identified by means of a four step focused systematic review and subjected to a detailed analysis to extract the important factors of resilient and sustainable group decision-making (R\&S GDM) (Supplementary Materials). The factors will need further investigation in the future to confirm their role; therefore, in this respect, the present study can be considered as a first step of a deeper and wider research. The particular objective is to investigate the identified factors connected with resilient and sustainable GDM in an industrial case. Accordingly, two groups of research questions are considered: G1RQ and G2RQ, general and specific, in turn:

\section{G1RQ}

G1RQ1: Are there any factors that make a group decision more resilient and sustainable?

G1RQ2: Do published studies consider resilience and sustainability just as criteria to be used in the evaluation models, or they also interpret them as attributes of the decision process and results, giving thus a meaning to the concept of resilient and sustainable group decision-making (R\&S GDM)?

G2RQ

G2RQ1: To what extent did the investigated company consider the identified factors in the group decisions?

G2RQ2: What was the impact of either considering or ignoring each factor in the decisions of the company?

In the next section a general methodology of the article and the detailed methodology of the systematic review and case study are explained. Then in Section 3 the results of the literature review and in Section 4 the results of the case study are reported. Section 5 provides a discussion on the findings. Section 6 highlights the managerial implications of this study and Section 7 wraps up the results and sets out the conclusions.

\section{Materials and Methods}

\subsection{General Methodology}

This paper presents a literature review on resilience and sustainability in the context of group decision-making (GDM) and includes two stages. In the first stage, we are going to survey the literature on GDM. The second stage of the study investigates the failure of group decision-making in a real 
company. In the first stage, the main goal is to explore in a systematic way the GDM methods that take into consideration the concepts of resilience and sustainability; we consider two different search strings including risks and important metrics. The string "metric" is chosen because it is important to find how the main factors that influence the effectiveness of group decisions have been structured and used. "Risk" is chosen because it is a key aspect that is discussed in resilient engineering and is often associated with group decision-making. Therefore, the survey will synthesize two different focuses including resilience and sustainability and discuss the practical group decision-making factor aim to have a resilient and sustainable decision.

In the second stage the main goal is to investigate the reasons behind failure through the concepts obtained in the previous stage and understand them. This discussion on the failures of the case study could lead us to the evaluation of the impact of the identified factors, related to resilience and sustainability in a real group decision.

\subsection{Methodology—Literature Review}

The first stage of the current investigation is the literature review that includes two phases. The first phase is a general study of the published research on GDM which shows connections with the concepts of sustainability and resilience, which we used for the focused literature study as inclusion criteria in the abstract examination phase and for the definition of the concept of "resilient decision". The results of the first phase are reported in Sections 3.1 and 3.2. The second phase is a systematic review focused on risks and metrics of GDM in the context of resilience and sustainability, performed by means of a novel approach. Figure 1 shows the focused systematic review process. This process is an original way to conduct a systematic review followed by the investigation of a case study to find confirmation of the key points highlighted in the literature. As Figure 1 illustrates, this process has four steps: Definitions, data collection, paper examination and analysis and discussion of the results.

The main theme of GDM in this paper is resilient and sustainable decision-making. Figure 2 illustrates the scope and limitations of the survey regarding the keywords. In Figure 2 the process of narrowing the scope is shown by the quantity of published documents in each of the subject areas. In the first step of the focused systematic review, Scopus was selected to review the state of art and existing knowledge. Two software were selected to work on the dataset: Mendeley and Microsoft Excel. Mendeley is a free reference manager provided by a company based in London, UK. Mendeley was selected because of its interconnection with Scopus; it is possible to import the results of advanced search in Scopus directly to the reference manager (see Annex A). Microsoft Excel was used as a spreadsheet to work with keywords, summarize the abstracts, cluster the articles regarding different criteria to find patterns and trends and as a feature calculation and graphing tool. The dataset produced by Mendeley was exported in CSV format to be used in Microsoft Excel. It was then possible to analyze the selected articles as they were retrieved and stored by Mendeley.

The second step of the systematic review is data collection (Figure 1). The strategy is to combine keywords to narrow the scope of the search. Therefore, the first step is to identify the keywords. This step is the most crucial part of the survey because the review is limited by the narrowed scope and the results depend on the focused selected papers (Figure 2).

Keyword selection has been done in the second step. First the important keywords are listed. The list includes a representative index of the main objectives. These keywords are group decision, method, resilience, sustainability, risk and metrics. The second step is implementing trial searches in Scopus while only limiting the search scope by keywords, sorting the results list according to relevance and checking the keywords in the first 100 papers to find the similar keywords that are used in scientific papers for the same context. The search query for Scopus advance search is as follows:

TITLE-ABS-KEY ("group decision" AND "method") AND (KEY (“Keyword*”))

* the keyword seat in this position

The snowball strategy was used to collect other similar keywords from the published literature. Table 1 shows the results of snowball keyword selection. 


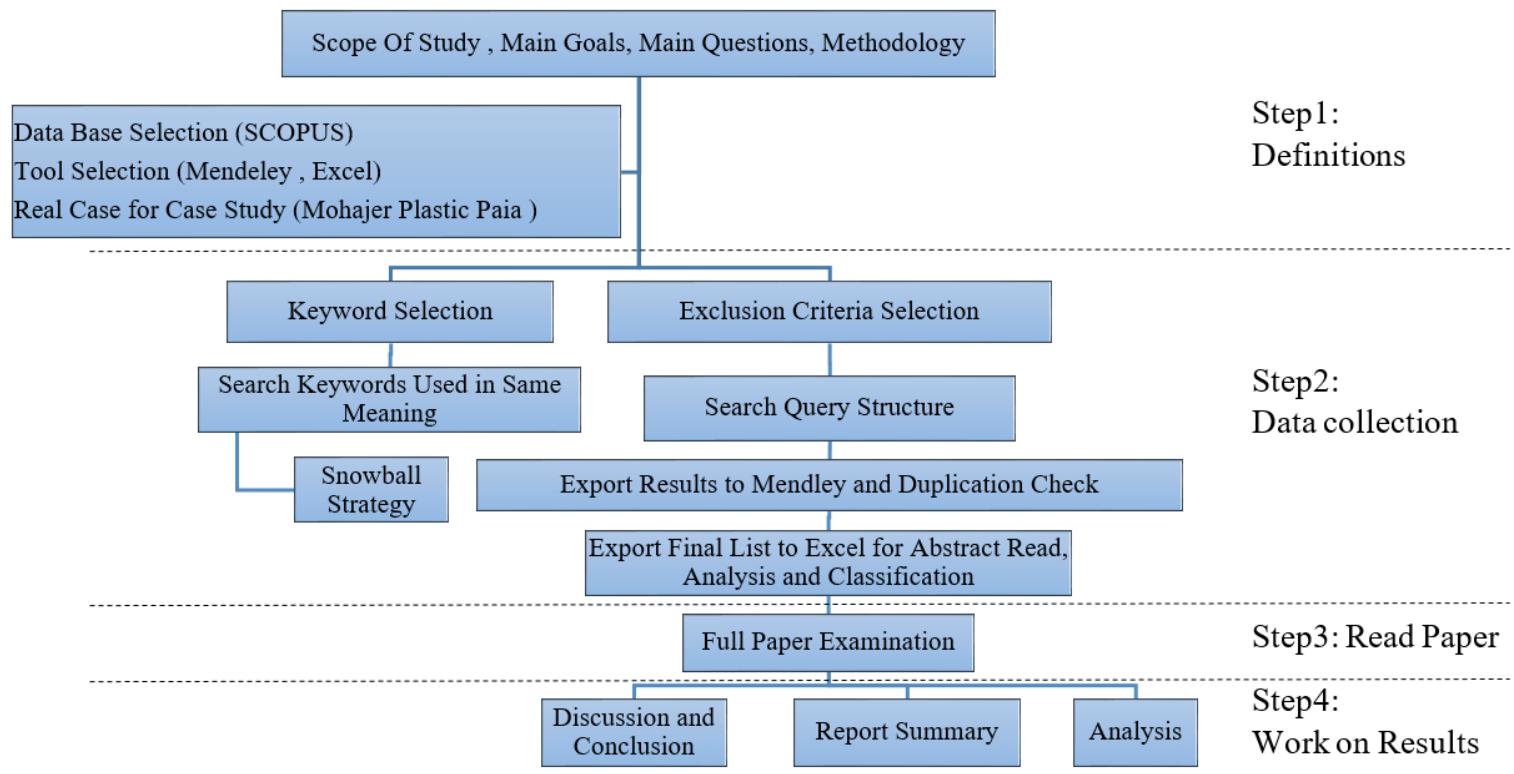

Figure 1. Systematic literature review process.

The advanced search query is used in Scopus search page; Scopus Search API supports a Boolean syntax, Boolean operators are implemented to combine the keywords. Scholarly sources in Scopus cover many document types such as reports, editorials, books, journal articles, conference papers and theses, but in this paper the query considers indexed journal articles especially because of the double blind review of the before publication and it a decision of the authors. Exclusion criteria of the search results include mathematics, art, physics and chemistry and the results are limited to English papers. Table 2 shows the two focused query strings. The results of the search are exported in Mendeley to undergo a duplication check. Thirty-one duplications were found in the results and eliminated from the list. Then the final list was exported in Excel to identify and classify the metrics and risks of R\&S GDM.

Table 1. Query Ssrings.

\begin{tabular}{ccccc}
\hline Selection Steps & & Keywords & \\
\hline $\begin{array}{c}\text { Primary } \\
\text { Keywords }\end{array}$ & Sustainability & Resilience & Risk & Metric \\
\hline Snowballed List & sustainable & resilient & threat, uncertainty & index, measure, indicator \\
\hline $\begin{array}{c}\text { Final Decision for } \\
\text { Search String }\end{array}$ & "sustainab" & "resilien*" & $\begin{array}{c}\text { "risk" OR } \\
\text { uncertainty" OR } \\
\text { "threat" }\end{array}$ & $\begin{array}{c}\text { "metric" OR "measure" } \\
\text { OR "index" OR } \\
\text { "indicator" }\end{array}$ \\
\hline
\end{tabular}

In the next step the abstracts were examined. The aim of this part is to find patterns, themes, conflicts and gaps. To do so, we made a list of questions (G3RQ) that were used in the abstract examination:

\section{G3RQ}

G3RQ1: Scope of the articles

What is the subject area of the article?

What problem is the article addressing?

G3RQ2: Methodology

What are the metrics for sustainability or resilience concepts and how are they defined?

What are the risks of ending up with an ineffective group decision? 
What are the key objectives and methods? Does the method need a prerequisite?

G3RQ3: Findings

What are the main findings, key insights and gaps of the study?

What are the limits, strengths and weaknesses of the research and the future challenges?

If the abstract did not give enough information to answer the above-mentioned questions or if the last of the above questions was raised after reading the abstract, the full paper was examined after the abstract. After reading the collected abstracts and full papers, we summarized the results of the analysis, classified the papers regarding the philosophical background and extracted the methods and important factors that impact on GDM. The results are reported in Section 4. Finally, all of the references were imported into the Zotero database to organize the reference list.

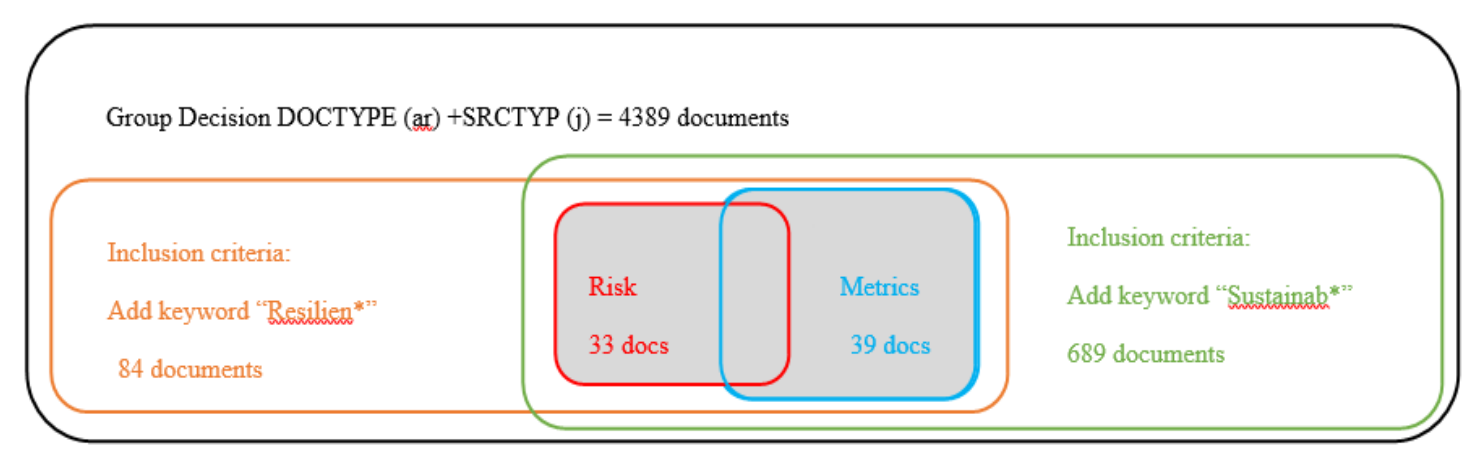

Figure 2. Scope and limitations of Survey.

Table 2. Query Strings.

\begin{tabular}{|c|c|c|}
\hline Focus & Query String & Result (Papers) \\
\hline Risk & $\begin{array}{l}\text { TITLE-ABS-KEY (“Group decision" AND "method") AND ("risk" OR } \\
\text { "uncertainty" OR “threat") AND ("resilien*") AND ("sustainab") AND } \\
\text { (SRCTYPE (j)) AND (DOCTYPE (ar)) AND (EXCLUDE (SUBJAREA, } \\
\text { "MATH") OR EXCLUDE (SUBJAREA, “ARTS") OR EXCLUDE } \\
\text { (SUBJAREA, "PHYS") OR EXCLUDE (SUBJAREA, “CHEM")) AND } \\
\text { (LIMIT-TO (LANGUAGE, "English")) }\end{array}$ & 39 \\
\hline Metrics & $\begin{array}{l}\text { TITLE-ABS-KEY (“Group decision”) AND ("metric" OR “measure" OR } \\
\text { "index" OR “indicator") AND ("resilien*") AND ("sustainab*”) AND } \\
\text { (SRCTYPE (j)) AND (DOCTYPE (ar)) AND (EXCLUDE (SUBJAREA, } \\
\text { “MATH") OR EXCLUDE (SUBJAREA, “ARTS") OR EXCLUDE } \\
\text { (SUBJAREA, “PHYS") OR EXCLUDE (SUBJAREA, “CHEM")) AND } \\
\text { (LIMIT-TO (LANGUAGE, “English")) }\end{array}$ & 33 \\
\hline
\end{tabular}

\subsection{Methodology—Case Study}

The selected case is a company that suffered the impacts of ineffective decisions and failed. The following data collection method was used in order to investigate the main factors of resilient decision-making, which are already identified in the systematic review stage of the current study. Firstly, general information about the company (Section 2.4) was collected through an interview with open questions. Then, the study focused on the reasons of the failure and the factors that affected group decisions in the company. Two online Skype interviews were conducted. The first online Skype interview was administered to collect data about the key decisions, their causes and the results. Open-end questions were asked to the executives, the members of the decision group, to identify the most problematic issues and the perceived reasons of ineffective decisions. The second online Skype interview was semi-structured and aimed to rank the ineffective decisions and then collect information 
about the causes and the effects of this ineffectiveness. The interviewees were asked to assign a level of impact to the causes of failure on a 1-10 scale (10: Maximum impact); the arithmetic mean was then used to rank such causes: Table 5 in the "Results" section shows in the last row the obtained rankings. The results are illustrated in Section 4.2.

\subsection{Case Company_Injection Molding Line In Tajikistan}

Mohajer Plastic Paia is an injection moulding company in Tajikistan, which faced bankruptcy mainly caused by poor decision-making. The company started production in 2007. The factory had six plastic injection moulding machines with different capacities (PA 100/250, PA 200/620, PA 300/100 and PA 500/2800). The company were using Parsian plastic injection moulding machines, which is an Iranian brand. The moulding production line had 14 different moulds to produce 11 sizes of plastic containers for agricultural productions transportation and four different sizes of bucket of paint.

\section{Literature Review Results}

\subsection{Resilient and sustainable decision-making}

Resilience is a recent concept which is popular in ecology, social science, technology and engineering. The bond between ecological concerns and planning was established in 1971 [1] and in 1975 Haber presented the difference between resiliency and stability and proposed a methodological approach in which ecological resiliency information provides a decision-making support resource [2]. That was the trigger for considering a combination of concepts including logistic evolution, resilience, stability, risks of disruption or crisis, socioeconomic risks, energy security, etc., in decision-making [3]. More specifically, Vertinsky introduced an ecological model of resilient decision-making in $1987 . \mathrm{He}$ used the same term "resilience" that ecologists use as a property of a system for the persisting ability of a system dealing with discontinuities in their environment [4]. A resilient decision can be defined as follows: "Well succeeded decisions adopted to guarantee a system's dynamic equilibrium, so as to correct, minimize or even avoid the effects of an unforeseen event" [5]. In the beginning, the implementation of the resilience concept in decision-making was more popular in water management, aquaculture and ocean science [6-9]; however, later on, researchers started to investigate organizational resilience $[10,11]$ and sustainability.

The primary integrations of sustainability in decision-making were proposed in the early 1990s [12,13], where the concept was considered as an evaluation dimension. Sustainable decision-making tries to assess the outcomes of a decision against the three pillars of sustainability (environment, social and economic). The interest for sustainability-based decisions increased substantially after 2006 and now there are more than 26 thousands documents which are related to both the sustainability and decision-making subject areas. However, in a 2018 study, Dong et al. highlighted that environmental impacts are still scarcely considered in decision-making [14]. On such accounts, it can be remarked that both aspects (resilience and sustainability) play a key role in strategic decision-making. Studying multiple economic, environmental and social indices increased recently [15] and, in the most recent years, researchers have started to consider combinations of political, socio-economic and environmental aspects in decision-making [16] in both the production and service sectors [17]. Implementing this new concept of decision-making could be fruitful in parallel with the sustainability agenda. In April 2019, the American Geophysical Union proposed the topic "Resilient Decision-Making for a Riskier World" in a special issue regarding a case study of drought in Nicaragua (AGU100) and different metrics introduced in the published case studies for resilience [18,19].

In the last two decades, the new concept, "resilient engineering", became a pivot point in sustainable development [20-22] and infrastructure planning [23,24] related decisions. It is a crucial necessity to create and sustain a resilient infrastructure. For instance, in the pathway toward sustainability and resiliency, Sinha and Graf presented an open source database which includes basic information for water and wastewater pipeline infrastructure [25]. This database provides 
information on pipeline condition assessment, renewal, technologies and management practices and cost information. It shows the different information that has already been used in infrastructure design and management and the complexity of infrastructural systems. This fact stressed the importance of resiliency of infrastructure and related decisions. There are other examples that investigate the risk, resilience and sustainability of infrastructure lifecycle contexts [26,27]; and in other cases the researchers took into account geotechnical information [28], resilient structural material [29], safety [30] and even climate change for future infrastructural resilience [31]. These examples show the interdisciplinary and complexity of these decisions and the investigations reveal the importance of implementing resilient engineering and its prerequisites such as resilient decision-making. However, sustainable development and infrastructure related decisions are usually made by a group of decision makers, thus requiring further investigation on group decision-making processes.

Figure 2 shows that there are more than 4000 published articles associated with group decision, the largest part of which was issued in the last two decades. This testifies to the recent strong interest in this topic. More specifically, 84 articles regarded resilience and almost 700 articles considered sustainability. Notwithstanding these numbers, investigations on resilience and sustainability in the context of group decision are scarce. The next section provides a literature review on group decision-making and in Section 3.3 attention is focused specifically on published research related to R\&S GDM.

\subsection{Group Decision-Making}

The first studies on GDM were published in the late 1950s in psychology. Torrance addressed the importance of harmony, congeniality and agreement in group work and the effect of willingness of some members to disagree with other members of a group in decision-making [32]. Then Ziller emphasized the characteristics of group decisions under uncertainty; for instance some members' reactions to the alternatives could be in contrast to the condition in which the leader alone makes the decision [33]. Group decision-making became a more popular topic in the 1960s [34]; researchers studied group decision-making under conditions of realistic complexity [35], combining statistical tools with GDM [36], GDM in the presence of risk [37] and the factors that impact the speed of GDM [38]. Then in the early 1970s different methods were implemented in GDM, such as a modified version of the Delphi process [39], a Q-sorting psychometric method for classifying items [40] and Coleman's linear model [41].

The late 1980s and early 1990s were a transitional period in which the adoption of multi-criteria decision-making methods was investigated [42-44]. From this point forward, many GDM studies were mainly focused on Multi-Criteria Decision-Making (MCDM) methods. Some authors have suggested extensions of existing methods like TOPSIS [45,46], FMEA [47] and DEMATEL [48]. More recently, an increasing inclination to use fuzzy MCDM is evident [49-53]. The fuzzy approach takes into account the inherent ambiguity of human judgment and perception [54,55]. For instance, Uztürk et al. used multi-granular linguistic information because of the different degrees of knowledge between stakeholders who are the members of a decision-making group [52].

GDM requires discussion, negotiation and deliberation between the members of the group. Therefore, to reach an acceptable decision that reflects the sometimes conflicting opinions within the group, all members should ideally declare their preferences [56]. In several actual situations, some of the partners do not participate in the decision-making process directly. This could affect decision-making because some information could be crucial but the active participants could be unaware of it. Bourgeois defines Management Information System (MIS) as an information system used to support decision-making and coordinate, control, analyze and visualize information in an organization, especially in a company [57].

The potentials of information systems in aiding problem solving have already been studied and introduced under the concept of Group Decision Support Systems (GDSS) [58]. More recent studies have investigated the usage of MIS as an intelligent decision system that can support group decision-making [59]. In general, research underlines the fact that information flow and storage is 
an important factor in decision-making. Nevertheless, it would be important to investigate more profoundly the role played by information in GDM and verify if it is one of the main factors that influence the resilience of group decisions.

\subsection{Resilient and Sustainable Group Decision-Making (RES GDM)}

The selected 38 papers are here surveyed. The literature review presents the trend of publications, the subject areas of the published paper in R\&S GDM, the methods that take into consideration the sustainability issues in GDM and the risks in the GDM process; finally, it identifies the main factors of effective GDM. An organized pattern will be discussed, which gives a new interpretation of existing GDM methods in light of sustainability and resilience.

\subsubsection{General View on the Selected Articles}

Putting the selected articles in chronological order discloses the sharp raise of the importance of the issue and the need of investigating GDM from multidisciplinary perspectives. Figure 3 shows the published articles by year. The first paper published in 2004 [60] shows that GDM plays a role in improving the social pillar of sustainability. The subject area of this article is bio-cultural conservation and proposes some approaches that are useful for improving the efficacy of consultative processes within conservation programmes. Wilson focused on four main themes, "1) the purpose of the consultative group; 2 ) the nature and types of group membership; 3 ) the decision-making procedures within the group; and 4) the impact of location on group decisions" [59]. He maintained that as long as consultation is approached in a philosophically honest way, producing ecological integrity and social justice will be possible. This was a reason behind considering group decision-making as a means of participation, in which the members of the group and the process of decision-making becomes a method to improve social factors of sustainability. Figure 3 depicts a slight increase from 2004 to 2017; however, the steep rise of the number of publications started in 2017 and, after that year, the quantity of publications doubled each year. This sharp increase shows the interest of researchers in GDM considering resilience and sustainability in the last decade.

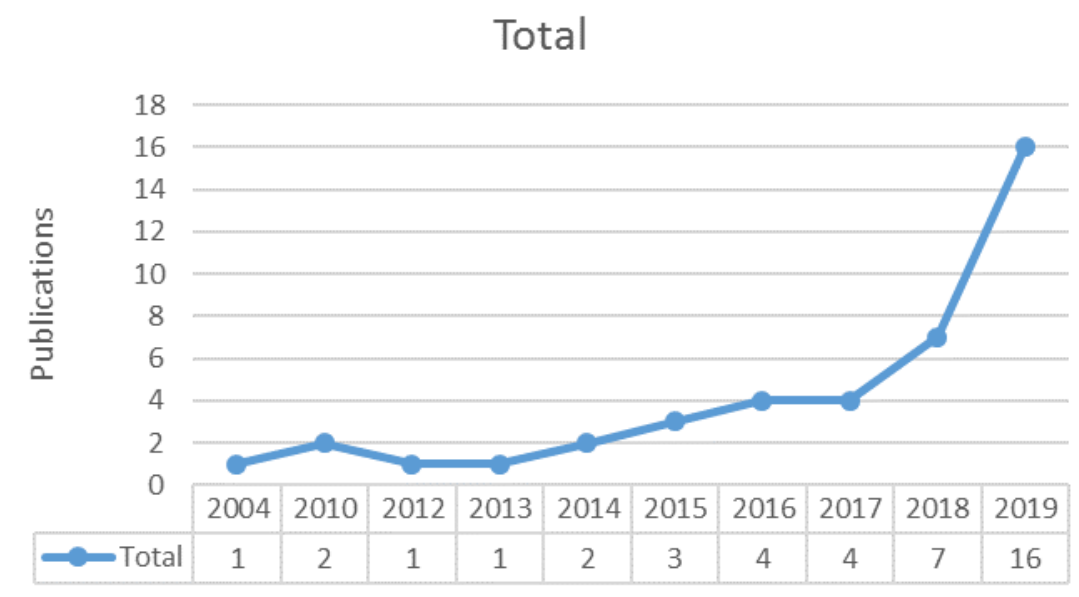

Figure 3. Selected publications in chronological order.

In this study, we consider sustainability and resilience as two main categories and then classify the articles regarding the risk management methods and metrics that are associated with the sustainability pillars and resilience. Figure 3 shows the scope of the articles.

Table 3 shows that the majority of the published work is associated with environmental issues (20 papers). The values in the last line of Table 3 show that the sustainability pillars and resilience concept have been considered in supply chain, city planning and disaster management more than in other topics. In city planning, researchers mostly focused on sustainability of transportation in 
cities and emergency management including seismic risk mitigation and resilience in coastal cities. Moreover, Table 3 illustrates that in $48 \%$ of cases, the authors considered both the sustainability pillars and resilience in GDM.

Table 3. Scope of the articles.

\begin{tabular}{|c|c|c|c|c|c|}
\hline Subject Area & Environment & Social & Economic & Resilience & Total \\
\hline Bio-cultural conservation & & 1 & & & 1 \\
\hline Building material selection & 1 & & & & 1 \\
\hline City planning & 3 & 1 & 1 & 2 & 3 \\
\hline Consensus level in a group & & & 1 & 1 & 2 \\
\hline Cost line & 2 & 1 & 1 & 1 & 2 \\
\hline Culture & & 1 & & 1 & 1 \\
\hline Development studies & & & 1 & & 1 \\
\hline Disaster management & 2 & 2 & 1 & 1 & 3 \\
\hline E-commerce & & & 2 & & 2 \\
\hline Energy sector & 1 & 1 & & & 1 \\
\hline Facility location & 2 & & 1 & & 2 \\
\hline Information, data, cyber security & & 1 & & 2 & 2 \\
\hline Infrastructure & & & 1 & & 1 \\
\hline Land use management & & 1 & & & 1 \\
\hline Organizational resilience & & & & 1 & 1 \\
\hline Partner selection & & & 1 & 1 & 1 \\
\hline Resilient strategies & 1 & & & 2 & 2 \\
\hline Safety & 1 & & 1 & & 1 \\
\hline Satisfaction maximization of group members & 1 & & & & 1 \\
\hline Self confidence & 1 & & & 1 & 1 \\
\hline Settlement resilience & 2 & 2 & 1 & 2 & 2 \\
\hline Supply chain & 2 & 4 & 3 & & 4 \\
\hline Water supply and waste management & 1 & 1 & & & 2 \\
\hline Grand total & 20 & 16 & 15 & 15 & 38 \\
\hline
\end{tabular}

\subsubsection{Methods and Metrics}

In 2019, Chen claimed that environment, natural resources, health and comfort of inhabitants are important criteria in the selection of building material [61]; he developed a novel hybrid multi-criteria group decision-making model based on Quality Function Deployment (QFD) and ELECTRE III. The business simulation game is another method, employed by Phadoongsitthi et al. in 2017 in GDM, that discloses the effects of national culture on GDM [62]. In this study, the authors remarked the existence of differences in the approach to cooperation among teams from Japan, China, Hong Kong and Thailand.

In 2019, Setiyowati et al. aimed to develop a Group Decision Support System (GDSS) to identify development priorities in six regions [63]. They combined two important factors that usually influence the regional development priorities and used a combination of GDM concepts: MVHAC cluster technique and the item-based cluster hybrid method. In the economic development sector, focused on E-commerce, two processes were introduced in 2019. First, Satisfaction maximization of group negotiation and deviation minimization of system coordination utilized by Yong et al. [64] and second a "novel fuzzy group decision method, which not only integrates QFD and an improved version of technique for Order Preference by Similarity to the Ideal Solution (TOPSIS) but also combines the qualitative analysis and quantitative analysis," introduced by Liu [65]. However, Chen et al. used satisfaction maximization of group members in a different sector [66]. Looking for environmental benefits and competitive advantages, they proposed a hybrid model for evaluating the sustainable value requirement. The proposal is a combination of the fuzzy set, rough set, decision-making trial and evaluation laboratory and analytical network process methods.

$\mathrm{Wu}$ (2016) used traditional ELECTRE-III under an intuitionistic fuzzy environment to an offshore wind power station site selection in the energy sector [67]. Qin et al. proposed TODIM, which handles information in the form of crisp numbers [68]. Two years after TODIM, Tadić et al. [69] conducted the most recent study on the selection of the most appropriate locations by a two-objective genetic 
algorithm (GA) and they claimed this is the most suitable method for the same routing issues. GA is a fruitful method to find the optimal solution; and Arsovski et al. [70] also used a combination of the fuzzy group decision-making problem and GA. In this case, the authors calculated organizational resilience potential factors (ORPFs) relative importance first and then they used GA to find the near optimal enhancement of ORPFs' values. Arsovski et al. studied enhancement of organizational resilience towards 120 Small and Medium Enterprises (SMEs). The importance of resilient strategy selection is here crucial.

Besides Arsovski, three other articles used fuzzy multiple criteria decision-making for complex decision systems in strategy selection:

1. Fuzzy analytical hierarchy process (FAHP) with the aim to select the appropriate resilient strategy for seaport operations [71];

2. Triangular and trapezoidal linguistic data and fuzzy multiple criteria decision-making in strategic supplier selection [72];

3. Combination of Intuitionistic Fuzzy Analytic Hierarchy Process (IF-AHP) and Ideal Solution (IF-TOPSIS) in order to partner selection [73].

Another implication of TOPSIS is used for wastewater treatment plan selection by applying an intuitionistic fuzzy set and then ranking various plans [74]. Another more complex method, employed in the decision-making process to balance water supply-demand strategies used a novel three phase approach [75]. The first phase is data collection; the second phase is problem structuring. They used the SODA method for problem structuring which includes surveying alternatives (supply and demand) and criteria; and then structured a model regarding the results of the survey. The third phase is the decision-making process using PROMETHEE II, integer linear programming (LIP) and sensitivity analysis.

The Analytical Hierarchy Process (AHP) is another popular method to support GDM. Mostofi Camare and Lane implemented AHP in a comprehensive resilience study [76]. They considered all pillars of sustainability including environmental, economic, social and cultural dimensions, aiming to estimate vulnerability, resilience and adaptive capacity measures associated with adaptation strategies in coastal communities.

Janssen is the only researcher that used an agent-based model in 2010 (ABM) in a population aggregation study [77]. He focused on an ancient settlement to study the long-term vulnerability of small-scale human societies. In this study, ABM was used to evaluate small-group decision-making on movements.

\subsubsection{Risk Management}

The project management body of knowledge (PMBOK) defines "risk" as an uncertain event which could have a positive or negative effect on the objectives [78]. The importance of risk management in sustainability studies has been particularly highlighted in decisions associated with the transition to sustainability, where the effects of accepting some risks in this transition have been investigated [79]. Martins and colleagues used MCDM in a group decision model in 2012 [80]. They presented a model based on a geographic information system (GIS) to evaluate the social vulnerability to seismic risk. In their investigation, they recommend the integration of social vulnerability indexes into seismic risk mitigation policies. This integration of social indexes into risk mitigation policies was a novel approach.

Two papers investigated GDM in cost line area resilience. Levy in 2010 focused on cost line resilience and used Drama Theory II (DT II) [81]. Levy upheld important characteristics of this method. He used this method because "DT II emphasizes that decision-makers engage in a rational-emotional process". Chen et al. introduced the new concept of group decision support systems as an emergency management support tool [82]. Licuanan et al. studied two issues in coastlines: Climate change and human activities [83]. The main objective was to identify the consequences of these issues such as marine flooding and erosion, besides identifying measures to minimize the impacts of these two issues 
on coastline areas. The tool introduced by this group in 2015 suggests engaging more stakeholders in participatory planning and group decision-making as this provides opportunities for learning about the issues. There are three articles on other subjects associated with disaster management [84-86].

The subjects are evacuation decision-making in wild fire, a risk-based emergency group decision method for haze disaster and flood adaption. Nguyen et al. in 2019 studied individual and group evacuation decision-making separately [84]. On the other hand, Loos and Rogers in 2016 showed that utility functions can demonstrate the role of individual decision-maker values in decision outcomes [85]; however, they conclude that MCDM ensures that decision makers consider multiple benefit qualities of natural capital projects.

Another example of decisions made by individuals in joint objectives is decision-making in joint infrastructures. For example, development of joint irrigation as an infrastructure in agriculture industry increasingly depends on individual investment decisions of farmers. The "make" decision is based on their current knowledge and understanding. However, researchers claim that it is ultimately a group decision [87].

Wilmer et al. in 2018 used a data oriented group decision in the land use management sector [88]. They analyzed meeting transcripts, interviews and focus group data related to stakeholder group decision-making. However, in data oriented decision-making, data security is defined as a risk. To manage the risk of mis/disinformation, which influences the final decision, Nielsen et al. in 2019 suggested providing a mapping of how information affects the decision-making context [89]. Another problem in group decision-making is information security. Regarding the study by Bharathi in 2017, data brokering, global exposure to personal data and lack of governance-based security design are the top three risk factors in this case [90].

In the supply chain sector, two articles have completely different focuses on sustainable supply chain management considering social and economic aspects. Both articles, published in 2019, show an increase of research interest in this sector regarding resilience and sustainability. Samani et al. studied a completely different supply chain network [91]. This paper is focused on the blood supply chain network which is a crucial network associated with healthcare systems in society. This supply chain network has a great social impact and also its economic effect on society is important. In the proposed model the authors considered risk mitigation and used quantitative factors aiming to minimize the loss of product freshness and total cost of the network.

On the other hand, in a well-known topic of supply chain management, Bai et al. considered economic, environmental and social sustainability dimensions in supplier selection [92]. The authors claim that social sustainability issues have received relatively minor investigations compared to the economic and environmental sustainability dimensions. They proposed a social sustainability decision framework in this article and provided a case study on the novel group decision-making approach, a grey-based multi-criteria decision-support tool composed of the 'best-worst method' (BWM) and TODIM.

\subsubsection{Main factors}

It is worth remarking that, in the reviewed literature, different authors name the key factors taken into consideration for evaluation or analysis purposes differently. The terms "index," "measure," "metric," "factor" or "indicator" are used and, in many cases, a clear distinction of meaning is not made in the paper. This fact required using the different terms as keywords in the systematic literature review.

Wilson in 2004 studied bio-cultural conservation and concluded that it is crucial to carry out a consultation in a philosophically honest and rigorous fashion [60]. This means that "honesty" is an important factor in assessing the performance of decision-making. Honesty is a human moral characteristic and a social factor that plays an important role in a decision's success. Classical decision-making models do not incorporate the role and influence of honesty; in fact, only three papers were found in SCOPUS that study the effect of honesty in group decision-making: A significant gap in the research on this topic remains $[93,94]$. 
Marleau Donais in 2019 focused on the popular advocate "streets for everyone" in a workshop and introduced novel support decision-making [95]; he also emphasized being transparent and improving communication of the outcome. The body of knowledge on the impact of human psychological behaviors in decision-making is not completely structured yet. The positive effects of "transparency" in environmental impact assessment, with the establishment of explicit goals in decision-making in committees, the effectiveness of dialogues and communications at all levels and the increasing capabilities for communicative actions have been already discussed [96-98]. Thus, transparency can be considered another meaningful factor of R\&S GDM.

Liu et al. in 2019 considered "self-confidence" as a component of human psychological behavior [99]. They applies this new index to the environmental pollution emergency management decision-making. They implemented self-confident fuzzy preference relations to express the experts' evaluations and, in a case study, they designed a self-confidence score function. The case study aimed to identify the best solution for environmental pollution emergency management; but the authors concluded that the proposed method is feasible and effective in general. In general, self-confidence is an individual's subjective evaluation of their own worth [100]. This positive or negative evaluation of the self is interrelated with concepts of self-efficacy and an individual's beliefs about their capacity to influence the events [101]. This concept is also crucial between group decision members because it affects the final decision of each member [102].

Two articles in 2019 studied the behavioural characteristics that exist in group decision-making. Tang et al. [103] and Liu et al. [64] considered the consensus level of the group members as an important index in GDM. The five-step process for decision-making that Tang et al. presented is as follows:

1. Obtaining ordinal preferences;

2. Classifying all decision-makers into several subgroups using the ordinal k-means clustering algorithm;

3. Measuring consensus levels of subgroups and the global group using novel ordinal consensus indexes;

4. Providing suggestions for decision-makers to revise preferences using feedback strategies;

5. Obtaining final decision results.

Altogether, having a shared opinion, among the members of a decision group, about the problems at stake enables the group to reach their goals; consensus level can then be considered another key factor of R\&S GDM.

Tadic et al. in 2017 studied environmental protection and seaport safety considering competitive advantage and long-term sustainability [104]. They proposed a modified fuzzy extended analytic hierarchy process and finally concluded future improvement lay on benchmark and knowledge sharing. Knowledge sharing could be defined as an index that measures the information flow between the decision makers in a group and its influence on the decision-making performance. There are two important aspect regarding this factor. The first aspect is the sensation of the group members; in a group of decision makers, DMs' sense of group identity and personal responsibility lead the members to share their knowledge and experience [105]. The second aspect is the channel of knowledge exchange. Modern information and telecommunication technology is available to support such exchanges across time and distance barriers [106]. In short, the exchange of information among decision makers is a vital component of the knowledge-management process in group decisions and knowledge sharing is an important factor of R\&S GDM.

Supply chain sustainability management is rather new but very popular among researchers and there are still many gaps in the literature and methods. Osiro et al. in 2018 implemented a new metric to fill the gap of considering the degree of difficulty of collecting data in supply chain studies [107]. They proposed a combination of techniques-Hesitant Fuzzy Linguistic Term Sets (HFLTS) and QFD—with the aim of providing a group decision model in supply chain sustainability management for selecting metrics. In brief, the evaluation based on a range of linguistic expressions regarding data collection 
and its difficulties (information availability, human resource, time required and other resources) led to a better representation of judgments. Therefore, degree of difficulty of data collection is another factor of the R\&S GDM.

In a different sector, Pishdar et al. studied the Internet of things and its challenges in supply chain management in 2015 [108]. They used rough group decision-making and trial evaluation laboratory (DEMATEL) and finally provided a group of suggestions for managers. This paper suggests security policies and emphasizes the importance of security risk assessment. This result is significant and shows that data security level could be an index in group decision-making. Data security means safeguarding digital data from destructive forces, unwanted actions of unauthorized users and unauthorized disclosure of confidential information [109]. In effect, data security considerations including data storage location, access and modifications regarding the information that is used in the group decision processes of a company influence the performance of final decisions.

In conclusion, a closer look at the identified factors shows that they are attributes of the group decision-making activity, not criteria hat are used in the decision process. The seven key factors, identified in the literature as the main attributes of R\&S GDM, are honesty, proper self-confidence level, transparency, communication and knowledge sharing, degree of difficulty of collecting data, data security and consensus. In the next section the results of the case study are reported.

\section{Case Study}

\subsection{Case Study Foundation}

This case was selected as it well represents a situation where the main decisions should have been made in a joint decision-making process involving all partners. A group was responsible for administering and managing the company, but there was no management information system to share the information between the decision makers. The decisions, which had the highest impacts on the bankruptcy of the company, were taken in absence of one of the partners.

The main goal of the case study here is to investigate the potential reasons of the failure of the group decision-making and the effect of the identified factors, discussed in the previous section, on group decisions in a small company and the issues which caused the failure in this production company. Often, senior managers are responsible for high impact decisions, which sometimes should be taken even if one of the key decision makers is not available, as in the case study.

\subsection{Ineffective Decisions}

The analysis of the key decisions taken by the company suggests a classification of the ineffective decisions into three main categories: Poor decisions in procurement, human resource management (HRM) and contracts with third parties (Table 4). The reasons of ineffective decisions are ranked according to the respondents and illustrated in Table 5.

Table 4. Ineffective decisions.

\begin{tabular}{|c|c|c|}
\hline Categories & & Decisions \\
\hline \multirow{2}{*}{ procurement } & 1. & Purchase of inappropriate injection moulds \\
\hline & 2. & Purchase of low quality raw material \\
\hline HRM & 1. & Poor HRM \\
\hline \multirow{3}{*}{ contracts } & 1. & Presell contracts \\
\hline & 2. & Rental contracts (rent the machines to the other companies) \\
\hline & 3. & $\begin{array}{l}\text { Provide and sign poor contracts in terms of text of the contract, } \\
\text { content and concept (from professional and legal point of view) }\end{array}$ \\
\hline
\end{tabular}


Table 5. Reasons of ineffective decisions and ranking.

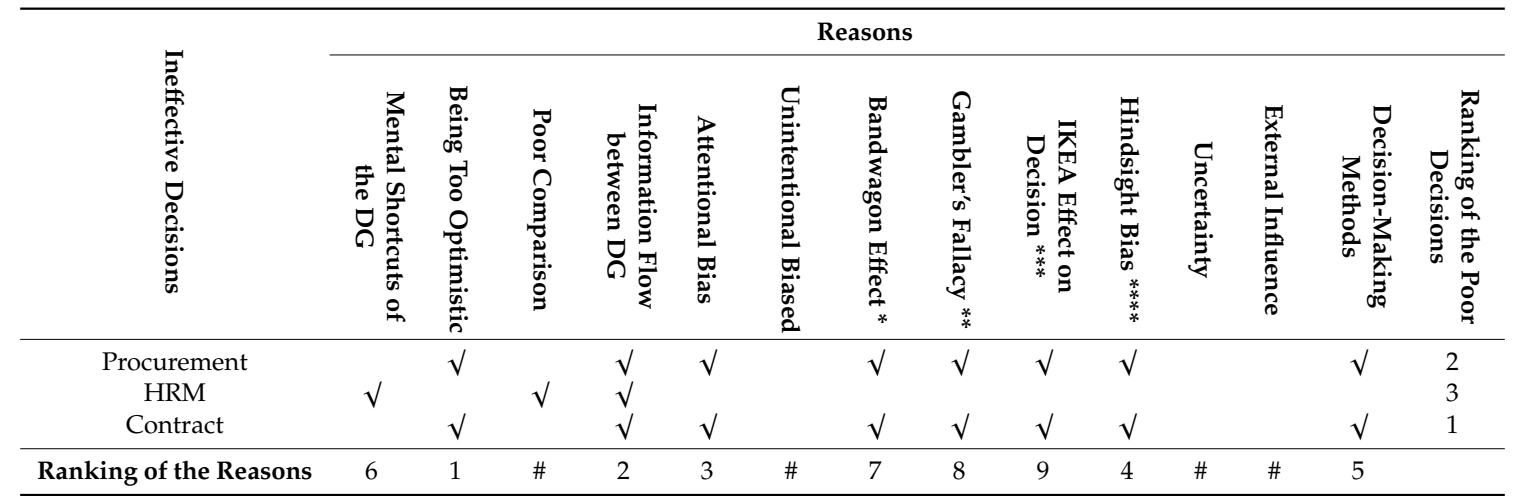

* The bandwagon effect is a psychological phenomenon in which people do something primarily because other people are doing it. ${ }^{* *}$ If something happens more frequently than normal during a given period, it will happen less frequently in the future. ${ }^{* * *}$ The IKEA effect is a cognitive bias. ${ }^{* * * *}$ DMs overestimate their ability to have predicted an outcome that could not possibly have been predicted. \# Regarding the respondents, these reasons had no effect (or neglectable) on the Ineffectiveness of the GD in the case company.

\section{Discussion}

The technical details in procurement are very important because a wrong purchase could impose dramatically negative outcomes. In small companies, quality control is more under the responsibility of an individual than a department, and the role of the technical experts is crucial in decision-making both before purchase, to ensure a complete list of requirements, and also after the purchase, to control the quality of the purchased items. In the specific case, wrong procurement of the moulds not only caused extra cost in terms of the price of the moulds, which was above the market price, but also some indirect costs, in particular related to the replacement of wrong moulds and double logistic operations.

Supply chain management is another key point and could affect the efficiency of the company during production and costs. In this company, just one of the partners (a member of the decision group) was familiar with the reliable channels of the supply of the raw material. In fact, wrong purchases were one of the principal mistakes, made in the absence of the other partners.

In small companies, human resources are possibly the most important factor for reaching efficiency in production. Poor HR management is irrecoverable. Not only all physical activities in production lines depend on human resources, but human resource management also affects production planning because decision makers consider the available manpower and skills before making decisions about increasing or decreasing the production in a specific period. Especially when technical skills are important, the absence of an expert or poor task assignment to the workers could decrease efficiency. In this company, one of the managers was not familiar with the skills and potential of the personnel. Consequently, when other partners were not in the company for long periods, he made poor decisions about task assignment to the available human resources.

Presell contracts need production planning. In small companies, production capacity is limited and usually difficult to increase in the short-term. Since the main products of the company are plastic containers for agricultural produce (fruits and vegetables), the demand is subject to seasonality. One of the poor decisions was to presell contracts in high seasons and overload the production line to produce more and compensate the production amount and contracts. However, over-production could damage the machines and moulds. This could result in extra costs for the overhaul of moulds and maintenance of machines. Because of this, presell contracts put the production under pressure and ended in serious damage to the machinery and equipment of the production line. This overload resulted in discontinuous production and, after a while, the company lost customers and long-term contracts. Meanwhile, renting the injection-moulding machines or moulds to other production companies could have the same impact with overloading the production line. To sum up, making wrong contracts and overloading the production lines call forth unforeseen major overhaul, extra maintenance cost and 
loss of market share. Last but yet important, writing and signing a contract raise legal responsibility. Therefore, they need special skills to provide a proper contract in terms of the text of the contract, content and concept (both from a professional and legal point of view).

Table 5 shows that cognitive bias is the most important reason of decision failures. Moreover, Bandwagon Effect has high rank, which means that also the rate of uptake personal beliefs and ideas increases the more in individuals that they have already been adopted by other members of the group. Some members made decisions primarily because other companies were doing it without considering the differences between the companies. On the other hand, high rank of Gambler's Fallacy and Decision-Making Methods depict the members made decisions without considering future uncertainty. As for the case study, beside Attentional Bias, a major cause of inadequate decisions was "over self-confidence:" one of the decision group members based his decisions only on personal inference from the past events; indeed, he did not communicate with the others to collect the information that would have been useful to support the final decisions.

In small companies, each member of the decision-making group plays a crucial role. Serious problems could ascend if one of the members take a day off or take break for a period for emergency reasons, unless the other members of decision group have clear information about his/her role and how they can fill the gap when he/she is not present. Especially in decision-making, all members of the management group have significant experience, information or skills, and their absence in the decision-making process could cause fundamental problems in production, planning and management. In this situation, an integrated management information system seems necessary to avoid any problematic decision in absence of one of the members. The main goal of using a management information system in this case is to avoid mistakes and subsequently to increase the value and profits of the business. Table 4 illustrates the reasons of the poor decisions which had been made by one of the members of the decision group. Grey boxes show the reasons that are associated with each poor decision in first column. Being too optimistic is a personal characteristics of the decision maker, which affects only two of the poor decision categories. In summary, the most important reason is possibly the information flow between decision makers, which influences all categories of poor decisions. This fact emphasizes the necessity of an information system in this situation to avoid them.

\section{Managerial Implication}

Group decision-making presents some specific features that must be considered; in particular, the decision cannot be attributable to any single individual but it is a result of the knowledge produced by and opinions of all the participants. In order to acquire information, useful to support decision-making, process it and, finally, take a decision, the participants may use MCDM methods to evaluate options against a set of evaluation criteria. It is worth remarking that the identified seven factors, highlighted in Section 3.3.4 (Honesty, Proper self-Confidence level, Transparency, Communication and Knowledge sharing, Degree of difficulty of collecting data, Data security and Consensus), are reported in the examined literature as indexes, metrics, measures or indicators of successful group decision-making, not as criteria to be employed in MCDM methods. Therefore, they can be interpreted as attributes of R\&S GDM: a R\&S GDM process is then a GDM process that embodies them. In summary, R\&S GDM is a specific type of GDM whereall the members of the decision group, by considering the seven factors, aim to make GDM sustainable and resilient. a:.

All of the members of the decision group should contribute to the above mentioned seven factors and, in this respect, the figure of a group leader plays a crucial role. It has been observed that people management skills and team work are two key managerial competences [110]. As a result, providing the appropriate milieu for the members of the decision group is an important role of leaders. Specifically, those who emerge as being very good leaders often have important qualities in preparing the prerequisites of team work and also group decision. In addition, the leader should possess a strong understanding of the company's products/services, processes, goals and the group decision members to be able to put into practice the attributes of R\&S GDM. This fact introduces a new role of the leader: 
To inspire, motivate, mentor and direct the decision group members to enable the seven factors of R\&S GDM.

Another measure enabling R\&S GDM is empowerment. It has been already proven that employee empowerment enhances employee performance [111,112]. Menon developed an integrative psychological approach for employee improvement [113]; on the other hand, individual empowerment increases team performance [112-115]. Current study highlights that decision-making group member empowerment would be a necessity to reach resilience in group decisions. As a result, sustainable and effective group decisions need a novel empowerment context, which is "Decision Makers Empowerment," aiming to increase the group decision effectiveness by improving the seven factors in decision group members.

General consensus among all members of a decision group is often unachievable in practice; however, various methods have been introduced in order to arrive at consensus in a group. The traditional method is removing the outliers: The group members with very different opinions are removed. This might possibly result in the loss of some precious ideas and in an impact on the sense of belonging in the organization. The results of the present study specifically suggest that the traditional method inversely affects the resilience of the group decision: Removing a member from a group in a specific decision can cut the information flow, weaken the knowledge sharing factor and influence the self-esteem of the member. A different method to reach consensus, without negatively affecting $R \& S$ GDM, is eliminating the outlier opinions, instead of the member of the decision-making group, in three steps: The consistency checking process, the consensus reaching process and the selection process [116]. Other authors suggest that considering the decision-making group as a social network could enhance the consensus level [117]. Some consensus degree models have been introduced that could be fruitful to monitor and measure the consensus level and reach the maximum consensus [118-120].

Finally, it must be noted that the factor "communication and knowledge sharing" includes two concepts that are related with information flow between the group members. The information system and information fluidity then play an important role in R\&S GDM. In this respect, the measurement of the MIS effectiveness and level of information fluidity could be indicators of the resilience and sustainability of GDM in the organization and help a possible transition of actual GDM processes towards R\&S GDM.

The empirical analysis of the role played by the seven factors in actual decision-making processes is an avenue of research that is required to confirm their benefits for producing more sustainable and resilient decisions. This would also suggest improvements in the organizational management of the operational and functional levels of the companies.

\section{Future Scope of Study and Limitation}

The present study was conducted in two stages. In the first stage, a systematic review was implemented to identify the most effective factors of the R\&S GDM. Evidently this is a significant gap in this subject area; however, the related studies are increasing sharply and another systematic review could be a future work to investigate "if new factors will be appended to the results of this list in future". The second stage was a case study. The main limit of this stage was the size of the company and the location of the case company. This company was a small enterprise production company located in a developing country. The general validity of the outcomes of the study is therefore debatable. Confirmations of the results could only come from further case studies, particularly concerning larger decision groups, bigger companies and other countries.

\section{Conclusions}

The systematic review of the scientific literature shows a lack in the resilience and/or sustainability of GDM with only 38 published papers. On the other hand, the body of knowledge on resilient decision-making is also still ambiguous. The main factors that have significant impact on sustainable and resilient GDM are as follow: 
1. Honesty

2. Self-confidence

3. Transparency

4. Communication and knowledge sharing.

5. Degree of difficulty of collecting data

6. Data security

7. Consensus

The systematic process for the literature survey, introduced and implemented in this paper, could be a systematic model for similar studies aiming to extract information from the literature and structure it by defining the key aspects.

A closer look at Tables 4 and 5 and the results shows that over self-confidence in the members of a group leads the decisions to failure. The case study (Table 5) points out that communication problems and knowledge sharing were obvious in all three classes of problematic decisions (Table 3). Weak information flow raised the lack of resilience in group decision-making; as a result, misaligned decisions in the partnership situation in that company were the main reason for the failure. Regarding this failure, weak information flow causes misaligned decisions. Information flow plays a crucial rule on R\&S GDM and the level of fluidity of information could be a performance index for a group decision. However, information flow was not the only problem of the communication between the members, the interviews unveiled that lack of transparency in the existing communications was another significant problem in the decision-making process of this company. Lack of transparency is a problem, but in some decisions, this issue can compound the problem of information flow too.

Last but yet important, in the case study we could not find any evidence of the R\&S GDM factors in the principal decision-making activity of the company: Ignoring the attributes of resilience and sustainability in group decision-making could result in ineffective decisions and consequently in the failure of the enterprise.

Supplementary Materials: The selected papers CSV file are available online at https://drive.google.com/file/d/ 1LXBgZJycDc8AfUA6WYOyHhm0Oclv4vcf/view?usp=sharing.

Author Contributions: For this research article, two authors cooperated. A.A.A. contributed in defining the research questions, the scope and main objectives; he set clear measurement priorities, data collection, and interviews and provided material, conducted the literature review, data analysis, and data visualization, interpret Results, and wrote the draft of the paper. E.P. defined the research questions, the scope and main objectives, supervised the literature review, data analysis, data visualization, refined the final draft of the paper. All authors have read and agreed to the published version of the manuscript.

Funding: This research received no external funding.

Acknowledgments: We acknowledge Sharareh Mohajeri, CEO of the Mohajer Plastic Paia for her kind support and giving permission to perform this academic study.

Conflicts of Interest: The authors declare no conflict of interest.

\section{References}

1. Holling, C.S.; Goldberg, M.A. Ecology and planning. J. Am. Inst. Plann. 1971, 37, 221-230.

2. Haber, D.; King, J.; Long, G. Ecological resiliency as applied to environmental planning and impact assessment. Proc. Annu. Environ. Eng. Sci. Conf. 1975, 305, 307-316.

3. Ursu, I.; Vamanu, D.; Gheorghe, A.; Purica, I.I. Socioeconomic risk in development of energy systems. Risk Anal. 1985, 5, 315-326. [CrossRef]

4. Vertinsky, I. An ecological model of resilient decision-making: An application to the study of public and private sector decision-making in Japan. Ecol. Model. 1987, 38, 141-158. [CrossRef]

5. dos Reis, M.Í.; Borges, M.; Gomes, J.O. Identifying resilient actions in decision-making during emergencies. In Encyclopedia of Decision Making and Decision Support Technologies; Information Science Reference (an imprint of IGI Global): Hershey, PA, USA, 2008; pp. 434-442. 
6. Beck, M.B. Applying systems analysis in managing the water environment: Towards a new agenda. Water Sci. Technol. 1997, 36, 1-17. [CrossRef]

7. Hall, J.W.; Davis, J.P. Sources and implications of uncertainty for coastal managers. Water Environ. J. 2001, 15, 103-108.

8. Scopus-Ocean and Coastal Management. Available online: https://www.scopus.com/sourceid/28333? origin=resultslist (accessed on 27 February 2020).

9. Hanna, S.S. User participation and fishery management performance within the pacific fishery management council. Ocean Coast. Manag. 1995, 28, 23-44. [CrossRef]

10. Knops, F.; Kumar, J.; Neilson, G.; Tusa, D. Survival of the Fittest. Total Telecom. 2004, 36-37.

11. Mallak, L.A. How to Build a Resilient Organization. In Proceedings of the industrial engineering solutions 1997 conference, Miami Beach, FL, USA, 17-18 May 1997; pp. 170-177.

12. Labonté, R. Econology: Integrating health and sustainable development part two: Guiding principles for decision-making. Health Promot. Int. 1991, 6, 147-156.

13. Allen, P.; Dusen, D.V.; Lundy, J.; Gliessman, S. Integrating social, environmental, and economic issues in sustainable agriculture. Am. J. Altern. Agric. 1991, 6, 34-39.

14. Dong, Y.; Miraglia, S.; Manzo, S.; Georgiadis, S.; Sørup, H.J.D.; Boriani, E.; Hald, T.; Thöns, S.; Hauschild, M.Z. Environmental sustainable decision-making-The need and obstacles for integration of LCA into decision analysis. Environ. Sci. Policy 2018, 87, 33-44. [CrossRef]

15. Ruiz, A.; Guevara, J. Sustainable decision-making in road development: Analysis of road preservation policies. Sustainability 2020, 12, 872. [CrossRef]

16. Beiragh, R.G.; Alizadeh, R.; Kaleibari, S.S.; Cavallaro, F.; Zolfani, S.H.; Bausys, R.; Mardani, A. An integrated multi-criteria decision-making model for sustainability performance assessment for insurance companies. Sustainability 2020, 12, 789. [CrossRef]

17. Aghazadeh Ardebili, A.; Padoano, E.; Rahmani, N. Waste reduction for green service supply chain-The case study of a payment service provider in Iran. Sustainability 2020, 12, 1833. [CrossRef]

18. McPhail, C.; Maier, H.R.; Kwakkel, J.H.; Giuliani, M.; Castelletti, A.; Westra, S. Robustness metrics: How are they calculated, when should they be used and why do they give different results? Earths Future 2018, 6, 169-191. [CrossRef]

19. Béné, C.; Doyen, L. From resistance to transformation: A generic metric of resilience through viability. Earths Future 2018, 6, 979-996. [CrossRef]

20. Malkina-Pykh, I.G. Integrated assessment models and response function models: Pros and cons for sustainable development indices design. Ecol. Indic. 2002, 2, 93-108. [CrossRef]

21. Merad, M.; Marcel, F. Assessing the Governance of the Organizations: Risks, Resiliencies and Sustainable Development. In Proceedings of the 11th International Probabilistic Safety Assessment and Management Conference and the Annual European Safety and Reliability Conference 2012, PSAM11 ESREL 2012, Helsinki, Finland, 25-29 June 2012; Volume 5, pp. 4073-4082.

22. Hunt, J. Integrated policies for environmental resilience and sustainability. Proc. Inst. Civ. Eng. Eng. Sustain. 2009, 162, 155-167. [CrossRef]

23. Nelson, P.P. Assessing Resilience Impacts from Integrated above- and below-Ground Urban Infrastructure. In Proceedings of the North American Tunneling Conference, NAT 2018, Washington, DC, USA, $24-27$ June 2018; Volume 2, pp. 645-651.

24. Hansen, K.L.; Neale, B.S. Infrastructure Resilience in the UK: An Overview of Current Approaches, ICSI 2014: Creating Infrastructure for a Sustainable World. In Proceedings of the 2014 International Conference on Sustainable Infrastructure, Long Beach, CA, USA, 6-8 November 2014; pp. 23-32.

25. Sinha, S.; Graf, W. Design and Development of a Web-Based National Database for Water and Wastewater Pipeline Infrastructure Systems. In Proceedings of the Pipelines 2012: Innovations in Design, Construction, Operations, and Maintenance-Doing More with Less, Miami Beach, FL, USA, 19-22 August 2012; pp. $28-37$.

26. Dong, Y.; Frangopol, D.M. Risk, Resilience, and Sustainability Assessment of Infrastructure Systems in a Life-Cycle Context Considering Uncertainties. In Proceedings of the 12th International Conference on Applications of Statistics and Probability in Civil Engineering, ICASP 2012, Vancouver, BC, Canada, 12-15 July 2015.

27. Frangopol, D.M.; Soliman, M. Life-cycle of structural systems: Recent achievements and future directions. Struct. Infrastruct. Eng. 2016, 12, 1-20. [CrossRef] 
28. Nikolaou, S.; Antonaki, N.; Kourkoulis, R.; Gelagoti, F.; Georgiou, I.; Gazetas, G. Geotechnical Engineering Challenges in the Path to Resilient Infrastructure. In Proceedings of the Geo-Risk 2017, Denver, CO, USA, 4-7 July 2017; pp. 206-215.

29. MacKie, K.R.; Kucukvar, M.; Tatari, O.; Elgamal, A. Sustainability metrics for performance-based seismic bridge response. J. Struct. Eng. 2016, 142. [CrossRef]

30. Timashev, S.A. Infranetics: The New MAICS-Convergent Technology Science. In IOP Conference Series: Materials Science and Engineering 481, Proceedings of the IV International Conference on Safety Problems of Civil Engineering Critical Infrastructures, Ekaterinburg, Russian, 4-5 October 2018; IOP Publishing: Bristol, UK, 2019; p. 012023. [CrossRef]

31. Espinet, X.; Schweikert, A.; Chinowsky, P. Robust prioritization framework for transport infrastructure adaptation investments under uncertainty of climate change. ASCE ASME J. Risk Uncertain. Eng. Syst. Part A Civ. Eng. 2017, 3. [CrossRef]

32. Paul Torrance, E. Group decision-making and disagreement. Soc. Forces 1957, 35, 314-318. [CrossRef]

33. Ziller, R.C. Four techniques of group decision-making under uncertainty. J. Appl. Psychol. 1957, 41, $384-388$. [CrossRef]

34. Moscovici, S.; Zavalloni, M. The group as a polarizer of attitudes. J. Pers. Soc. Psychol. 1969, 12, $125-135$. [CrossRef]

35. Shure, G.H.; Rogers, M.S.; Meeker, R.J. Group decision-making under conditions of realistic complexity. Hum. Factors J. Hum. Factors Ergon. Soc. 1963, 5, 49-58. [CrossRef] [PubMed]

36. Stone, L.A. Use of a multiple regression model with group decision-making. Hum. Relat. 1963, 16, $183-188$. [CrossRef]

37. Bem, D.J.; Wallach, M.A.; Kogan, N. Group decision-making under risk of aversive consequences. J. Pers. Soc. Psychol. 1965, 1, 453-460. [CrossRef]

38. Joslyn, W.D.; Banta, T.J. Modifying speed of group decision-making without awareness of group members. Psychon. Sci. 1966, 6, 297-298. [CrossRef]

39. Rutherford, G.S.; Schofer, J.L.; Wachs, M.; Skutsch, M. Goal formulation for socio-technical systems. ASCE J. Urban Plann. Dev. Div. 1973, 99, 157-169.

40. Helin, A.F.; Souder, W.E. Experimental test of a q-sort procedure for prioritizing R\&D projects. IEEE Trans. Eng. Manag. 1974, EM-21, 159-164.

41. Blin, J.-M. Preference aggregation and statistical estimation. Theory Decis. 1973, 4, 65-84. [CrossRef]

42. Lee, W.W.-L. Multi-criteria policy analysis in marine mining. Int. J. Policy Inf. 1982, 6, 37-46.

43. Rao, J.R.; Tiwari, R.N.; Mohanty, B.K. Preference structure on alternatives and judges in a group decision problem-A fuzzy approach. Int. J. Syst. Sci. 1988, 19, 1795-1811. [CrossRef]

44. Dyer, R.F.; Forman, E.H. Group decision support with the analytic hierarchy process. Decis. Support Syst. 1992, 8, 99-124. [CrossRef]

45. Shih, H.-S.; Shyur, H.-J.; Lee, E.S. An extension of TOPSIS for group decision-making. Math. Comput. Model. 2007, 45, 801-813. [CrossRef]

46. Chen, C.-T. Extensions of the TOPSIS for group decision-making under fuzzy environment. Fuzzy Sets Syst. 2000, 114, 1-9. [CrossRef]

47. Boral, S.; Howard, I.; Chaturvedi, S.K.; McKee, K.; Naikan, V.N.A. A novel hybrid multi-criteria group decision-making approach for failure mode and effect analysis: An essential requirement for sustainable manufacturing. Sustain. Prod. Consum. 2020, 21, 14-32. [CrossRef]

48. Abdullah, L.; Zulkifli, N.; Liao, H.; Herrera-Viedma, E.; Al-Barakati, A. An interval-valued intuitionistic fuzzy DEMATEL method combined with Choquet integral for sustainable solid waste management. Eng. Appl. Artif. Intell. 2019, 82, 207-215. [CrossRef]

49. Fahmi, A.; Amin, F. Triangular cubic linguistic uncertain fuzzy topsis method and application to group decision-making. Soft Comput. 2019, 23, 12221-12231. [CrossRef]

50. Fahmi, A.; Amin, F.; Abdullah, S.; Ali, A. Approaches to multi-attribute group decision-making based on trapezoidal linguistic uncertain cubic fuzzy TOPSIS method. New Math. Nat. Comput. 2019, 15, $261-282$. [CrossRef]

51. Amin, F.; Fahmi, A.; Abdullah, S. Dealer using a new trapezoidal cubic hesitant fuzzy TOPSIS method and application to group decision-making program. Soft Comput. 2019, 23, 5353-5366. [CrossRef] 
52. Uztürk, D.; Romero, A.L.; Büyüközkan, G.; Martinez, L. Fuzzy linguistic integrated methodology for sustainable hospital building design. Adv. Intell. Syst. Comput. 2020, 1029, 1180-1188.

53. Demircioǧlu, M.E.; Ulukan, H.Z. A novel hybrid approach based on intuitionistic fuzzy multi criteria group-decision-making for environmental pollution problem. J. Intell. Fuzzy Syst. 2020, 38, 1013-1025. [CrossRef]

54. Capuano, N.; Chiclana, F.; Fujita, H.; Herrera-Viedma, E.; Loia, V. Fuzzy group decision-making with incomplete information guided by social influence. IEEE Trans. Fuzzy Syst. 2017, 26, 1704-1718. [CrossRef]

55. Kacprzyk, J. Group decision-making with a fuzzy linguistic majority. Fuzzy Sets Syst. 1986, 18, 105-118. [CrossRef]

56. Pérez, I.J.; Cabrerizo, F.J.; Alonso, S.; Dong, Y.C.; Chiclana, F.; Herrera-Viedma, E. On dynamic consensus processes in group decision-making problems. Inf. Sci. 2018, 459, 20-35. [CrossRef]

57. Bourgeois, D.T. Information Systems for Business and Beyond. In Saylor Academy Open Textbooks; Saylor Foundation: Washington, DC, USA, 2018.

58. McLeod, R.; Schell, G. Management Information Systems, 10th Edition. Available online: https://www.pearson.com/us/higher-education/program/Mc-Leod-Management-Information-Systems10th-Edition/PGM299161.html (accessed on 26 February 2020).

59. Turban, E.; Sharda, R.; Delen, D. Decision Support and Business Intelligence Systems, 9th ed.; Prentice Hall Press: Upper Saddle River, NJ, USA, 2010; ISBN 978-0-13-610729-3.

60. Wilson, W. Suggestions to foster effective consultation within conservation. Environments 2004, 32, 71-85.

61. Chen, Z.-S.; Martínez, L.; Chang, J.-P.; Wang, X.-J.; Xionge, S.-H.; Chin, K.-S. Sustainable building material selection: A QFD- and ELECTRE III-embedded hybrid MCGDM approach with consensus building. Eng. Appl. Artif. Intell. 2019, 85, 783-807. [CrossRef]

62. Phadoongsitthi, M.; Rompho, N.; Iwai, C.; Morita, M. Effects of national culture on group decision-making: A comparative study between Thailand and other Asian countries. Int. J. Econ. Bus. Res. 2017, 13, 110. [CrossRef]

63. Setiyowati, S.; Sumiati; Sutarti; Wibowo, A.H.; Rosalina, V.; Ai Munandar, T.A. Group decision support system to determine regional development priority using the item-based clustering hybrid method. J. Comput. Sci. 2019, 15, 511-518. [CrossRef]

64. Liu, Y.; Du, J.; Wang, Y. An improved grey group decision-making approach. Appl. Soft Comput. 2019, 76, 78-88. [CrossRef]

65. Liu, A.; Zhang, Y.; Lu, H.; Tsai, S.-B.; Hsu, C.-F.; Lee, C.-H. An innovative model to choose e-commerce suppliers. IEEE Access 2019, 7, 53956-53976. [CrossRef]

66. Chen, Z.; Ming, X.; Zhang, X.; Yin, D.; Sun, Z. A rough-fuzzy DEMATEL-ANP method for evaluating sustainable value requirement of product service system. J. Clean. Prod. 2019, 228, 485-508. [CrossRef]

67. Wu, Y.; Zhang, J.; Yuan, J.; Geng, S.; Zhang, H. Study of decision framework of offshore wind power station site selection based on ELECTRE-III under intuitionistic fuzzy environment: A case of China. Energy Convers. Manag. 2016, 113, 66-81. [CrossRef]

68. Qin, Q.; Liang, F.; Li, L.; Chen, Y.-W.; Yu, G.-F. A TODIM-based multi-criteria group decision-making with triangular intuitionistic fuzzy numbers. Appl. Soft Comput. 2017, 55, 93-107. [CrossRef]

69. Tadić, D.; Đorđević, A.; Aleksić, A.; Nestić, S. Selection of recycling centre locations by using the interval type-2 fuzzy sets and two-objective genetic algorithm. Waste Manag. Res. 2019, 37, 26-37. [CrossRef]

70. Arsovski, S.; Putnik, G.; Arsovski, Z.; Tadic, D.; Aleksic, A.; Djordjevic, A.; Moljevic, S. Modelling and enhancement of organizational resilience potential in process industry SMEs. Sustainability 2015, 7, 16483-16497. [CrossRef]

71. John, A.; Yang, Z.; Riahi, R.; Wang, J. Application of a collaborative modelling and strategic fuzzy decision support system for selecting appropriate resilience strategies for seaport operations. J. Traffic Transp. Eng. Engl. Ed. 2014, 1, 159-179. [CrossRef]

72. Haldar, A.; Ray, A.; Banerjee, D.; Ghosh, S. Resilient supplier selection under a fuzzy environment. Int. J. Manag. Sci. Eng. Manag. 2014, 9, 147-156. [CrossRef]

73. Büyüközkan, G.; Güleryüz, S. A new integrated intuitionistic fuzzy group decision-making approach for product development partner selection. Comput. Ind. Eng. 2016, 102, 383-395. [CrossRef]

74. Zhou, Z.; Dou, Y.; Zhang, X.; Zhao, D.; Tan, Y. A group decision-making model for wastewater treatment plans selection based on intuitionistic fuzzy sets. J. Environ. Eng. Landsc. Manag. 2018, 26, 251-260. [CrossRef] 
75. Cambrainha, G.M.; Fontana, M.E. A multi-criteria decision-making approach to balance water supply-demand strategies in water supply systems. Production 2018, 28. [CrossRef]

76. Mostofi Camare, H.; Lane, D.E. Adaptation analysis for environmental change in coastal communities. Soc. Econ. Plann. Sci. 2015, 51, 34-45. [CrossRef]

77. Janssen, M.A. Population aggregation in ancient arid environments. Ecol. Soc. 2010, 15. [CrossRef]

78. Rose, K.H. A guide to the project management body of knowledge (PMBOK@guide)—5th Edition. Proj. Manag. J. 2013, 44, e1. [CrossRef]

79. Aghazadeh ardebili, A.; Padoano, E.; Fatemeh, H. Prepare organizations to accept risks: A feasible risk management model. In Proceedings of the 7th International Conference Production Engineering and Management, Pordenone, Italy, 28-29 September 2017; pp. 75-86.

80. Martins, V.N.; e Silva, D.S.; Cabral, P. Social vulnerability assessment to seismic risk using multicriteria analysis: The case study of Vila Franca do Campo (São Miguel Island, Azores, Portugal). Nat. Hazards 2012, 62, 385-404. [CrossRef]

81. Levy, J.K. Negotiation support for environmental disaster management: Drama theory II and the survival of Louisiana's indigenous gulf coast tribes. J. Nat. Resour. Policy Res. 2010, 2, 371-388. [CrossRef]

82. Chen, Y.; Zhao, X.; Rich, E.; Luna-Reyes, L.F. Decision models and group decision support systems for emergency management and city resilience. Int. J. E Plan. Res. 2018, 7, 35-50. [CrossRef]

83. Licuanan, W.Y.; Samson, M.S.; Mamauag, S.S.; David, L.T.; Borja-del Rosario, R.; Quibilan, M.C.C.; Siringan, F.P.; Sta. Maria, M.Y.Y.; España, N.B.; Villanoy, C.L.; et al. I-C-SEA change: A participatory tool for rapid assessment of vulnerability of tropical coastal communities to climate change impacts. Ambio 2015, 44, 718-736. [CrossRef]

84. Nguyen, C.; Schlesinger, K.J.; Han, F.; Gür, I.; Carlson, J.M. Modeling individual and group evacuation decisions during wildfires. Fire Technol. 2019, 55, 517-545. [CrossRef]

85. Loos, J.R.; Rogers, S.H. Understanding stakeholder preferences for flood adaptation alternatives with natural capital implications. Ecol. Soc. 2016, 21. [CrossRef]

86. $\mathrm{Li}, \mathrm{H}$. A risk-based emergency group decision method for haze disaster weather based on cumulative prospect theory. Int. J. Appl. Decis. Sci. 2018, 11, 334-351.

87. Nikkels, M.; Guillaume, J.H.A.; Leith, P.; Hellegers, P. Sharing reasoning behind individual decisions to invest in joint infrastructure. Water 2019, 11, 798. [CrossRef]

88. Wilmer, H.; Derner, J.D.; Fernández-Giménez, M.E.; Briske, D.D.; Augustine, D.J.; Porensky, L.M. Collaborative adaptive rangeland management fosters management-science partnerships. Rangel. Ecol. Manag. 2018, 71, 646-657. [CrossRef]

89. Nielsen, L.; Tølbøll Glavind, S.; Qin, J.; Faber, M.H. Faith and fakes-Dealing with critical information in decision analysis. Civ. Eng. Environ. Syst. 2019, 36, 32-54. [CrossRef]

90. Bharathi, S.V. Prioritizing and ranking the big data information security risk spectrum. Glob. J. Flex. Syst. Manag. 2017, 18, 183-201. [CrossRef]

91. Samani, M.R.G.; Hosseini-Motlagh, S.-M.; Ghannadpour, S.F. A multilateral perspective towards blood network design in an uncertain environment: Methodology and implementation. Comput. Ind. Eng. 2019, 130, 450-471. [CrossRef]

92. Bai, C.; Kusi-Sarpong, S.; Badri Ahmadi, H.; Sarkis, J. Social sustainable supplier evaluation and selection: A group decision-support approach. Int. J. Prod. Res. 2019, 57, 7046-7067. [CrossRef]

93. Tanford, S.; Cox, M. The effects of impeachment evidence and limiting instructions on individual and group decision-making. Law Hum. Behav. 1988, 12, 477-497. [CrossRef]

94. Khalid, A.; Beg, I. Role of honesty and confined interpersonal influence in modelling predilections. Soft Comput. 2020, 24, 1497-1509. [CrossRef]

95. Marleau Donais, F.; Abi-Zeid, I.; Waygood, E.O.D.; Lavoie, R. Assessing and ranking the potential of a street to be redesigned as a Complete Street: A multi-criteria decision aiding approach. Transp. Res. Part A Policy Pract. 2019, 124, 1-19. [CrossRef]

96. Morrison-Saunders, D.A.; Bailey, D.J. Transparency in environment impact assessment decision-making: Recent developments in Western Australia. Impact Assess. Proj. Apprais. 2000, 18, 260-270. [CrossRef]

97. Levy, G. Decision-making in committees: Transparency, reputation, and voting rules. Am. Econ. Rev. 2007, 97, 150-168. [CrossRef] 
98. Wene, C.O.; Espejo, R. A Meaning for Transparency in Decision Processes. In Values in Decisions on Risk Proceeding; (NEI-SE-308); Andersson, K., Ed.; VALDOR: Stockholm, Sweden, 1999.

99. Liu, X.; Xu, Y.; Ge, Y.; Zhang, W.; Herrera, F. A group decision-making approach considering self-confidence behaviors and its application in environmental pollution emergency management. Int. J. Environ. Res. Public Health 2019, 16, 385. [CrossRef]

100. Snyder, C.R.; Lopez, S.J. Oxford Handbook of Positive Psychology; Oxford Library of Psychology: New York, NY, USA, 2009; ISBN 0-19-518724-5.

101. Bandura, A. Self-efficacy: Toward a unifying theory of behavioral change. Psychol. Rev. 1977, 84, 191. [CrossRef]

102. Hoffman, K.; Elwin, C. The relationship between critical thinking and confidence in decision-making. Aust. J. Adv. Nurs. 2004, 22, 8.

103. Tang, M.; Zhou, X.; Liao, H.; Xu, J.; Fujita, H.; Herrera, F. Ordinal consensus measure with objective threshold for heterogeneous large-scale group decision-making. Knowl. Based Syst. 2019, 180, 62-74. [CrossRef]

104. Tadic, D.; Aleksic, A.; Popovic, P.; Arsovski, S.; Castelli, A.; Joksimovic, D.; Stefanovic, M. The evaluation and enhancement of quality, environmental protection and seaport safety by using FAHP. Nat. Hazards Earth Syst. Sci. 2017, 17, 261-275. [CrossRef]

105. Cabrera, A.; Cabrera, E.F. Knowledge-sharing dilemmas. Organ. Stud. 2002, 23, 687-710. [CrossRef]

106. McNurlin, B.C.; Sprague, R.H. Information Systems Management in Practice; Prentice Hall PTR: Upper Saddle River, NJ, USA, 2001; ISBN 978-0-13-034073-3.

107. Osiro, L.; Lima-Junior, F.R.; Carpinetti, L.C.R. A group decision model based on quality function deployment and hesitant fuzzy for selecting supply chain sustainability metrics. J. Clean. Prod. 2018, 183, 964-978. [CrossRef]

108. Pishdar, M.; Ghasemzadeh, F.; Antucheviciene, J.; Saparauskas, J. Internet of things and its challenges in supply chain management; a rough strength-relation analysis method. EM Ekon. Manag. 2018, 21, 208-222. [CrossRef]

109. Summers, G.; Koehne, H. Data and databases. In Developing Databases with Access; Nelson Cengage Learning: South Melbourne, Australia, 2004; pp. 4-5. ISBN 978-0-17-018553-0.

110. Rajadhyaksha, U. Managerial competence: Do technical capabilities matter. Vikalpa 2005, 30, 47-56. [CrossRef]

111. Meyerson, G.; Dewettinck, B. Effect of empowerment on employees performance. Adv. Res. Econ. Manag. Sci. 2012, 2, 40-46.

112. Fernandez, S.; Moldogaziev, T. Empowering public sector employees to improve performance: Does it work? Am. Rev. Public Adm. 2011, 41, 23-47. [CrossRef]

113. Menon, S. Employee empowerment: An integrative psychological approach. Appl. Psychol. 2001, 50, $153-180$. [CrossRef]

114. Yang, S.-B.; Choi, S.O. Employee Empowerment and Team Performance: Autonomy, Responsibility, Information, and Creativity. Team Perform. Manag. 2009, 15, 289-301. [CrossRef]

115. Mathieu, J.E.; Gilson, L.L.; Ruddy, T.M. Empowerment and team effectiveness: An empirical test of an integrated model. J. Appl. Psychol. 2006, 91, 97. [CrossRef]

116. Liao, H.; Xu, Z.; Zeng, X.-J.; Xu, D.-L. An enhanced consensus reaching process in group decision-making with intuitionistic fuzzy preference relations. Inf. Sci. 2016, 329, 274-286. [CrossRef]

117. Herrera-Viedma, E.; Cabrerizo, F.J.; Chiclana, F.; Wu, J.; Cobo, M.J.; Samuylov, K. Consensus in group decision-making and social networks. Stud. Inform. Control 2017, 26, 259-268. [CrossRef]

118. Herrera, F.; Herrera-Viedma, E.; verdegay, J.L. A model of consensus in group decision-making under linguistic assessments. Fuzzy Sets Syst. 1996, 78, 73-87. [CrossRef]

119. Kaeprzzyk, J. A soft measure of consensts in the setting of partial preferences. Eur. J. Oper. Res. 1988, 34, 316-325. [CrossRef]

120. Fedrizzi, M.; Kacprzyk, J. An interactive multi-user decision support system for consensus reaching processes using fuzzy logic with linguistic quantifiers. Decis. Support Syst. 1988, 4, 313-327. [CrossRef]

(C) 2020 by the authors. Licensee MDPI, Basel, Switzerland. This article is an open access article distributed under the terms and conditions of the Creative Commons Attribution (CC BY) license (http://creativecommons.org/licenses/by/4.0/). 